\title{
Expression of Ebolavirus glycoprotein on the target cells enhances viral entry
} Balaji Manicassamy ${ }^{1,2}$ and Lijun Rong*1

\author{
Address: ${ }^{1}$ Department of Microbiology and Immunology, College of Medicine, University of Illinois at Chicago, Chicago, Illinois, USA and \\ ${ }^{2}$ Department of Microbiology, Mount Sinai School of Medicine, 1 Gustave L Levy Place, Box 1124, New York, New York, USA \\ Email: Balaji Manicassamy - balaji.manicassamy@mssm.edu; Lijun Rong* - lijun@uic.edu \\ * Corresponding author
}

Published: 8 June 2009

Virology Journal 2009, 6:75 doi:10.1186/1743-422X-6-75

This article is available from: http://www.virologyj.com/content/6/I/75

(C) 2009 Manicassamy and Rong; licensee BioMed Central Ltd.

This is an Open Access article distributed under the terms of the Creative Commons Attribution License (http://creativecommons.org/licenses/by/2.0), which permits unrestricted use, distribution, and reproduction in any medium, provided the original work is properly cited.
Received: I April 2009

Accepted: 8 June 2009

\begin{abstract}
Background: Entry of Ebolavirus to the target cells is mediated by the viral glycoprotein GP. The native GP exists as a homotrimer on the virions and contains two subunits, a surface subunit (GPI) that is involved in receptor binding and a transmembrane subunit (GP2) that mediates the virushost membrane fusion. Previously we showed that over-expression of GP on the target cells blocks GP-mediated viral entry, which is mostly likely due to receptor interference by GPI.

Results: In this study, using a tetracycline inducible system, we report that low levels of GP expression on the target cells, instead of interfering, specifically enhance GP mediated viral entry. Detailed mapping analysis strongly suggests that the fusion subunit GP2 is primarily responsible for this novel phenomenon, here referred to as trans enhancement.

Conclusion: Our data suggests that GP2 mediated trans enhancement of virus fusion occurs via a mechanism analogous to eukaryotic membrane fusion processes involving specific trans oligomerization and cooperative interaction of fusion mediators. These findings have important implications in our current understanding of virus entry and superinfection interference.
\end{abstract}

\section{Background}

Enveloped virus fusion with host membrane proceeds via a series of controlled steps which leads to fusion between viral and cellular membranes. The fusion process mediated by class I fusion proteins has been well characterized primarily from our understanding of the pre-fusion and post-fusion structures of influenza haemagglutinin (HA), parainfluenza viruses 3 and 5 F proteins, and HIV glycoproteins [1-9]. First, the receptor-binding subunit binds to its cognate receptor on the host cell surface. Second, the glycoproteins undergo dramatic conformational changes including exposure of the fusion peptide which inserts into the host target membrane, tethering the virions on the host membrane. Third, the fusion protein undergoes additional conformational change forming a coiled-coil structure or six-helix bundle in which the fusion peptide placed apposed to the transmembrane domain. This brings the viral and host membranes to close proximity resulting in the fusion of apposing membranes.

Ebola viral envelope glycoprotein (GP) is involved in mediating virus entry. Ebola GP, like other class I viral fusion proteins, is synthesized as a single polypeptide precursor called pre-GP $[10,11]$. Pre-GP undergoes modifications by $\mathrm{N}$-glycosylation and $\mathrm{O}$-glycosylation into a fully glycosylated form $\mathrm{GP}_{0}[12,13] . \mathrm{GP}_{0}$ is cleaved in the lateGolgi by furin-like proteases into GP1 and GP2. The newly formed $\mathrm{N}$-terminal end contains the putative 
fusion peptide[13,14]. On the virion surface GP is present as a trimer and contains two subunits: a surface subunit (GP1) that binds to the cell surface receptor and a transmembrane subunit (GP2) that mediates the virus-host membrane fusion[15]. Previously, we and others have reported that the N-terminal region of GP1 (roughly aa 33-180), referred to as receptor-binding domain or RBD, is involved in receptor binding [16-18]. The GP2 subunit contains an $\mathrm{N}$-terminal putative fusion peptide followed by heptad repeats (N-helix and C-helix, or coiled-coil) which are involved in the formation of the six-helix bundle structure during viral/cell membrane fusion $[19,20]$.

Several cellular factors, such as folate receptor $\alpha$, DCSIGN, L-SIGN, hMGL, and Tyro3 family members have been implicated in facilitating Ebola entry [21-26], but the primary receptor has not been identified yet. Based on the current understanding of Ebolavirus entry, Ebola infection is believed to be initiated by binding of GP1 to the cellular receptor(s). Once bound, the virus is endocytosed into the endosomes. In the endosomes, under low $\mathrm{pH}, \mathrm{GP}$ is cleaved by endosomal cysteine proteases such as cathepsin B and cathepsin $L[27,28]$. Specific inhibition of this cleavage event drastically affects virus entry[27]. It has been speculated that this cleavage event under low $\mathrm{pH}$ might acts as a trigger for GP2-mediated viral/cell membrane fusion. At the end of virus-host membrane fusion, the viral capsid is released into the cytoplasm and virus replication takes place.

Although Ebola and Marburg virus GP1 subunits share $35 \%$ overall sequence conservation [29], we and others have shown that Ebola and Marburg viruses are likely to share a common receptor or co-factor in viral entry $[16,17]$. Another piece of evidence is that transient overexpression of Ebola GP or Marburg GP in the host cells can specifically block both EGP/and MGP/HIV pseudovirus entry[30]. This is consistent with the observations that viral infections can render cells to become resistant to re-infection by the same virus or viruses using the same receptor. It is thought that in these cells, the newly synthesized glycoprotein forms a complex with the viral receptor and hence, there are fewer free viral receptors available for re-infection. This phenomenon of superinfection resistance or receptor interference has been observed among the retroviruses using the same receptor[31].

To further characterize the mechanism of Ebolavirus entry, in this study we have generated stable cells expressing EGP under a tetracycline inducible promoter. This system allows us to regulate EGP expression by modulating the concentration of inducer (doxycycline). Surprisingly, EGP expression in target cells specifically enhanced EGP/ HIV pseudotyped virus transduction. We have systematically mapped and characterized the functional domains in
EGP involved in this trans enhancement. Our results show that the fusion machinery, but not the receptor-binding, of Ebola GP, is responsible for this enhancement. Therefore, EGP expression in target cells displays a dichotomous property: it can specifically block EGP-mediated viral entry, which is mediated by the receptor-binding region of GP1, or it can specifically enhance Ebola GPmediated viral entry via the fusion machinery of GP, mostly by GP2. Based on these results, we propose a model for EGP mediated trans enhancement, which mirrors the current models of intracellular membrane fusion and cell-cell fusion. Furthermore, this study may have important implications on our understanding of virus entry and superinfection interference.

\section{Results \\ Expression of Ebola glycoprotein in HEK cells enhances transduction of EGPIHIV pseudovirions}

We previously demonstrated that transient transfection and over-expression of Ebola glycoprotein on target cells can specifically inhibit entry of EGP/HIV or Marburg glycoprotein (MGP)/HIV pseudovirus (Additional file 3, Figure S1; [30]). To better characterize the entry mechanism of these viruses, a HEK (293) cell line stably expressing the full length EGP under a tetracycline inducible promoter (EGP Tet-On) was generated. This system allows us to modulate EGP expression by varying the concentration of doxycycline (dox; an analog of tetracycline).

To examine the EGP induction profile, the EGP Tet-On cells were incubated with increasing concentrations of dox $(0,0.01,0.1,1 \mu \mathrm{g} / \mathrm{ml})$, and the EGP surface expression levels were measured by flow cytometry. Surface staining of these cells with a monoclonal anti-EGP antibody showed a dose-dependent increase in surface EGP levels as the concentration of dox increased (Figure 1A). Compared to the control Tet-On cells (empty vector, red), the uninduced EGP Tet-On cells showed a clear shift in mean fluorescent intensity (green), suggesting a low level of leaky EGP expression without induction. Nevertheless, increasing mean fluorescent intensities were detected as the concentration of dox was increased, indicating that EGP expression was induced by dox. The levels of surface EGP in the Tet-inducible system, even at $10 \mu \mathrm{g} / \mathrm{ml}$, was approximately 10 -fold lower than the transient overexpression in 293T cells (data not shown). Western blot analysis of the EGP Tet-on cells confirmed the dosedependent induction of EGP expression (Figure 1B). However, EGP expression was not detectable in the uninduced cells, likely due to lower sensitivity of Western blot analysis than flow cytometry. In addition, we did not observe any visible cytopathic effects of EGP expression on the EGP Tet-On cells. 
A

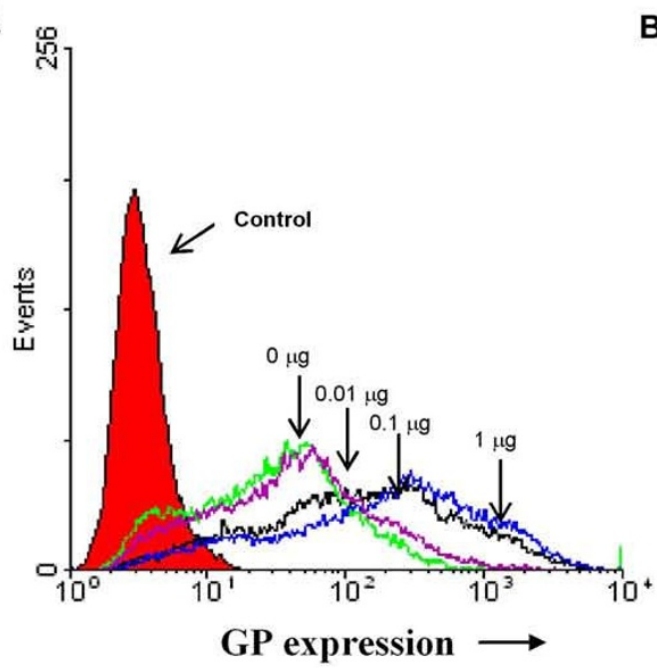

D
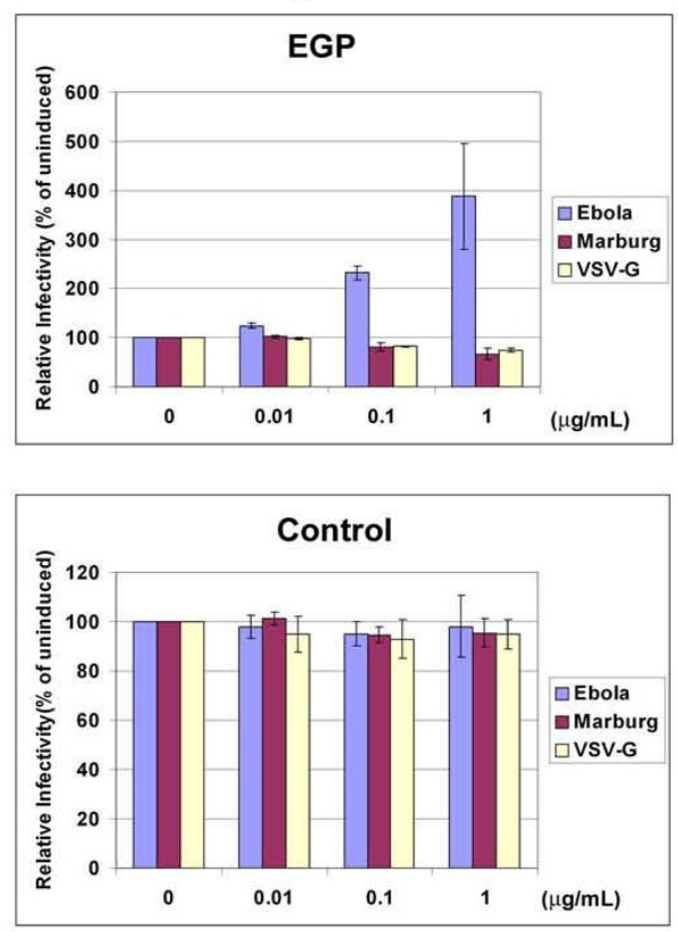

B

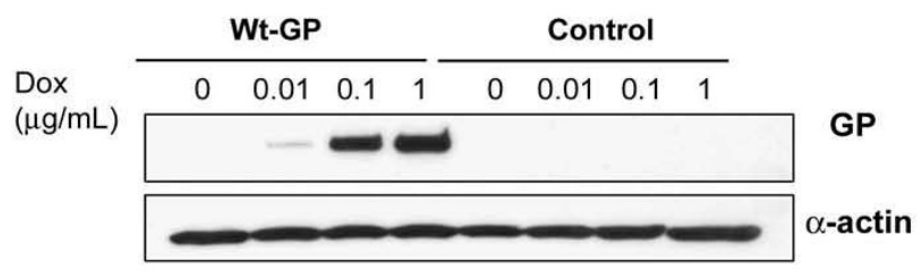

C HIV packaging construct

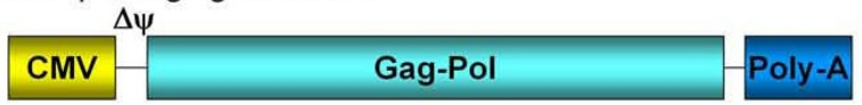

Envelope expression construct

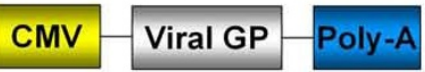

HIV reporter construct

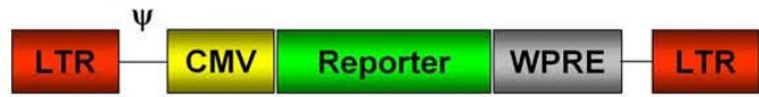

E

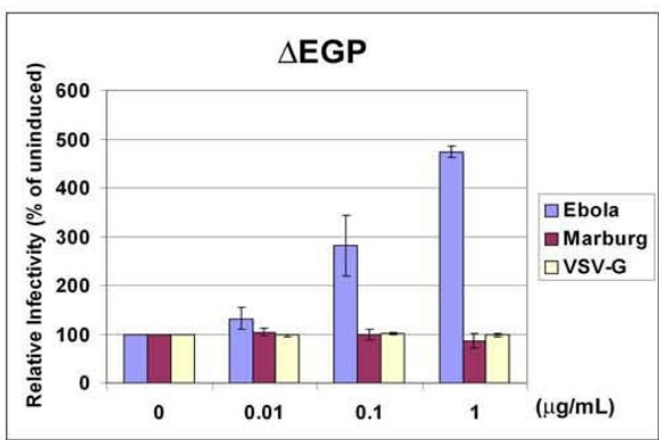

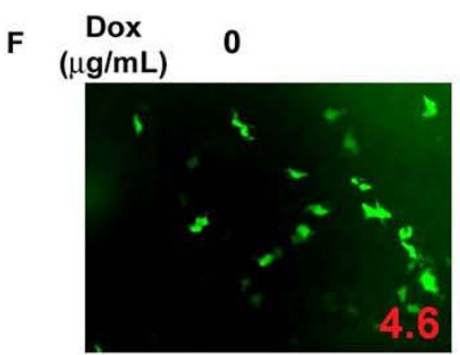

0.01

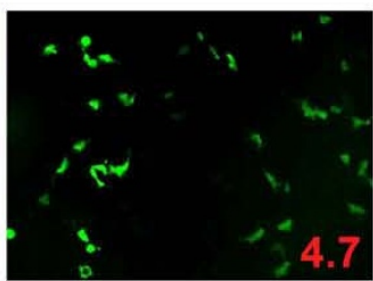

0.1 1
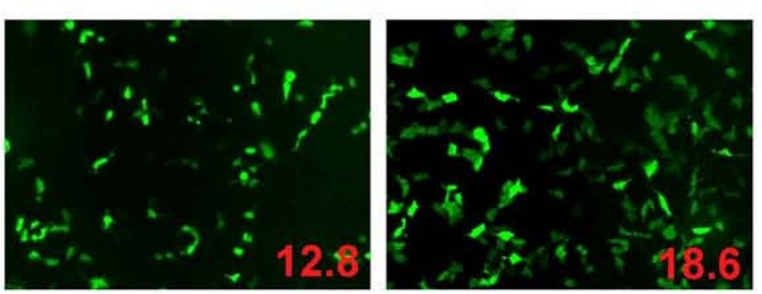

Figure I (see legend on next page) 
Figure I (see previous page)

EGP expression in target cells enhances EGP/HIV transduction. (A) Cell surface expression of EGP. EGP Tet-On cells were seeded in 12-well plates $\left(6 \times 10^{4}\right.$ cells/well) and EGP expression was induced with indicated concentrations of dox. After $24 \mathrm{~h}$ post-induction, cell surface EGP levels were analyzed by flow cytometry using an EGP monoclonal antibody. (B) Western blot analysis of EGP expression in Tet-On cells. EGP Tet-On cells were seeded in I2-well plates and induced with indicated concentrations of dox. Forty-eight hours post-induction, cell lysates were subjected to SDS-PAGE followed by immunoblotting using a EGP monoclonal antibody. (C) HIV pseudotyping constructs. HIV packaging construct encodes gag/pol genes required for virion assembly. Envelope expression construct encodes genes for EGP or MGP or VSV-G under the control of a CMV promoter. HIV reporter construct encodes the viral genomic RNA, carrying a luciferase or a GFP reporter gene. (D) Enhancement of EGP/HIV transduction by EGP expression in target cells. EGP or control Tet-On cells were seeded in 24-well plates (3 $\times 10^{4}$ cells/well) and induced with varying concentrations of dox. After $24 \mathrm{~h}$ post-induction, cells were challenged with EGP/ HIV, MGP/HIV or VSV-G/HIV pseudovirions carrying a luciferase reporter gene. The luciferase activities in the cell lysates were measured $48 \mathrm{~h}$ post-infection and are presented as percentage of the uninduced cells (100\%). Data represents an average of at least three independent experiments. Bars, standard deviations. (E) The mucin-like region in EGP is not required for enhancement. Tet-On stable cells with EGP mutant lacking the mucin-like region $(\Delta E G P)$ were induced with dox and challenged with pseudotyped virions carrying luciferase reporter. The luciferase activities are shown as relative percentage of the uninduced cells (100\%). Data represents an average of at least three independent experiments. Bars, standard deviations. (F) EGP Tet-On cells infected with EGP/HIV pseudovirions carrying a GFP reporter. The percentage of GFP expressing cells, shown in each panel as inserts, were quantified by flow cytometry.

To examine the effect of EGP expression on the target cell on EGP/HIV pseudovirus infection, the EGP Tet-On cells were induced with increasing concentrations of dox $(0$, $0.01,0.1,1 \mu \mathrm{g} / \mathrm{ml}$ ) for $24 \mathrm{hrs}$ and challenged with the EGP/HIV pseudovirions which were generated from the producer cells (293T) by transient transfection of three plasmids (Figure 1C). Forty-eight hours post-infection, the luciferase activities in the infected cells were determined as a measure of the pseudotyped virus transduction, since the HIV vector carries a luciferase reporter gene. Surprisingly, expression of EGP in the target cells enhanced, instead of blocking, the transduction of the EGP/HIV pseudovirions in a dox dose-dependent manner (Figure 1D, top). The luciferase activities in the target cells (expressed as relative infectivity, \% of uninduced cells) increased correspondingly as increasing concentrations of dox were used, reaching up to 4 -fold at $1 \mu \mathrm{g} / \mathrm{ml}$ of dox. In contrast, neither MGP nor VSV-G- mediated transduction was enhanced in these cells with dox induction (Figure 1D, top). Further, treatment of the control cells (empty vector) with dox did not affect EGP- or MGP- or VSV-Gmediated viral transduction (Figure 1D, bottom).

To further confirm and quantify the observed trans enhancement by EGP, the dox induced EGP Tet-On cells were challenged with the EGP/HIV pseudovirions carrying a green fluorescent protein (GFP) reporter instead of luciferase, and the GFP-positive cells were visualized by fluorescent microscopy (Figure $1 \mathrm{~F}$ ) and quantified by flow cytometry (Figure 1F, inserts). Increasing number of GFPpositive cells was detected as higher concentrations of dox were used for induction. The GFP-positive cells were about 4 -fold higher at $1 \mu \mathrm{g} / \mathrm{ml}$ of dox $(18.4 \%)$ than the uninduced cells $(4.6 \%)$, very consistent with the results described above using the EGP/HIV virus carrying the luciferase gene. These results demonstrate that EGP expression in the target cells can specifically enhance, rather than blocking, the EGP-mediated transduction.

\section{The mucin-like region of GPI is not required for trans enhancement of EGP-mediated transduction}

The C-terminus of Ebola GP1 contains a mucin-like region ( $~ 200$ residues in length) which is heavily glycosylated and is not required for viral entry $[12,16]$. To examine whether the mucin-like region was involved in enhancement, an HEK Tet-On cell line expressing $\triangle E G P$ $(\Delta 309-489)$, which lacks the mucin-like region, was generated. The induction profiles of the $\triangle \mathrm{EGP}$ in this cell line, examined by flow cytometry, were comparable to that of the Wt EGP (Additional file 4, Figure S2). Furthermore, like Wt EGP Tet-On cells, the $\triangle$ EGP Tet-On cells could specifically enhance the EGP-mediated, but not MGP- or VSV-G -mediated transduction in a dose dependent manner, up to approximately 5 -fold higher at a dox concentration of $1 \mu \mathrm{g} / \mathrm{ml}$ than the uninduced cells (Figure $1 \mathrm{E}$ ). These results indicate that the mucin-like region of EGP is not involved in trans enhancement of the EGP-mediated transduction.

\section{Trans enhancement by EGP is correlated with the entry susceptibility of the target cells}

To test whether the observed trans enhancement of EGP/ HIV transduction was dependent on the entry susceptibility of the target cells, the wt EGP Tet-On and the $\triangle$ EGP TetOn cell lines were derived from a susceptible cell line (HeLa) or a resistant cell line (Human T lymphocytes -Jurkat). Expression of wt EGP and $\triangle E G P$ in these cells were examined by both western blot analysis and flow cytome- 
try, and a dose dependent induction by dox was observed (data not shown).

Challenging the HeLa cells bearing either wt EGP or $\triangle \mathrm{EGP}$ with EGP/HIV pseudovirus led to a dose-dependent enhancement of transduction (Figure 2A), consistent with the results in the HEK cells described above. In stark contrast, expression of either wt EGP or $\triangle \mathrm{EGP}$ in Jurkat cells did not enhance the transduction efficiency of the pseudovirus (Figure 2B). Together these results suggest that (receptor) binding of the GP/HIV virions to the target cells is important for EGP-mediated enhancement.

\section{EGP expression on the target cells enhances EGPIMLV pseudovirion transduction}

To confirm that enhancement by EGP expression on target cells is independent of the HIV pseudotyping system, HEK Tet-On cells expressing either EGP or $\triangle \mathrm{EGP}$ induced with dox were challenged with murine leukemia virus (MLV)based pseudvirions (EGP/MLV) carrying a GFP reporter. It is clear that number of GFP-positive cells increased in a dox dose-dependent manner in HEK cells expressing either EGP or $\triangle$ EGP to levels similar to that observed with the EGP/HIV pseudovirions ( 3.5- 4 fold). In contrast, EGP/MLV transduction was not affected with dox treatment in control cells (Figure 2C). In addition, MGP/MLV or VSVG/MLV-mediated transduction was not affected in EGP or $\Delta$ EGP-expressing cells (data not shown). These results demonstrate that EGP-mediated trans enhancement of viral transduction is specific to EGP-bearing virions and independent of the pseudotyping system used for viral entry.

\section{Trans enhancement is more pronounced for coiled-coil mutants of GP2}

To further understand the mechanism of trans enhancement, HEK Tet-On cells expressing Wt EGP were challenged with the EGP/HIV pseudotyped viruses with mutation in different functional regions of EGP namely the receptor-binding domain (RBD), fusion peptide and coiled-coil region (Figure 3A). These EGP mutants encompassing different functional domains of the glycoprotein have been previsouly described to be similar to Wt EGP in protein expression and incorporation pseudoparticles (Additional file 6, Figure S4). However, they have distinct defects in different steps of viral entry (Table 1) [16]. It is apparent from Figure 3A that Wt EGP on the target cells significantly enhanced transduction of several coiled-coil mutant EGP/HIV pseudoparticles. Especially, mutants R580A, D629A, and F630A showed enhancement in infectivity nearly $824 \%, 1,188 \%$, and $789 \%$, respectively. Also, some of the RBD and fusion peptide mutants showed enhancements similar to Wt EGP/HIV particles (200\%). However, expression of Wt EGP in target cells did not significantly enhance the infectivity of mutant EGP/
HIV pseudoparticles that were severely defective in mediating viral entry (Infectivity less than $0.1 \%$ of Wt; Table 1 ). An exception to this was RBD mutant K95A, a receptorbinding mutant, whose transduction was not enhanced by Wt EGP. However, we observed enhancement for RBD mutants L57I and I170A, which are defective in postreceptor binding steps of entry (J Wang, BM and LR, Manuscript in preparation).

To thoroughly characterize this trans enhancement phenomenon, HEK Tet-On cells expressing fourteen EGP mutants were generated ( 3 in GP1, 5 in fusion peptide, and 6 in coiled-coil region; Additional file 4, Figure S2 and Additional file 5, Figure S3). HEK cell lines expressing a specific mutant EGP or wt EGP (induced with 0, or $1 \mu \mathrm{g}$ / $\mathrm{ml}$ of dox) were challenged with each of the fifteen different types of HIV pseudovirions bearing either mutant or wt EGP, and the luciferase activities of each infected cell line were determined and the results plotted in Figure 3B. Several interesting conclusions can be drawn from the data:

(1) No complementation was observed between severely defective mutants. The most impaired GP mutants expressed in target cells could not trans enhance viral entry mediated by GP mutations at other positions (same region or different regions) or themselves. In addition, at least partially functional EGP is required on both target cell and on the virions for trans enhancement. For example, mutants F535R and L561A are completely impaired in mediating viral entry, and thus they were unable to trans enhance either any other mutant or themselves.

(2) Trans enhancement is cooperative. A partially impaired GP on the target cells could nevertheless trans enhance viral entry mediated by the same defective GP. For example, Expression of L558A on the target cells was as good as wt GP in trans enhancing L558A-mediated viral entry. This phenomenon is also true for mutants R580A, D629A, and F630A, and other mutants. This is quite remarkable considering that these mutants are fairly impaired in their ability to mediate viral entry. For example, it was shown that F630A displayed less than 1\% of wt GP activity in mediating viral entry (see Table 1), but it could trans enhance just like wt GP (Figure 3B). The cooperative (but not complementary) feature of trans enhancement provides a nice explanation for specificity: Ebola GP on the target cell can only enhance Ebola GP, but not Marburg GP-mediated viral entry (see Discussion).

(3) As described above, higher enhancement indices (EIs) were observed for coiled-coil region mutants. For example, mutant L558A on the target cells could increase R580A-mediated viral entry by almost 19 folds (EI = $1894 \%)$. These results further strengthen the hypothesis 
A
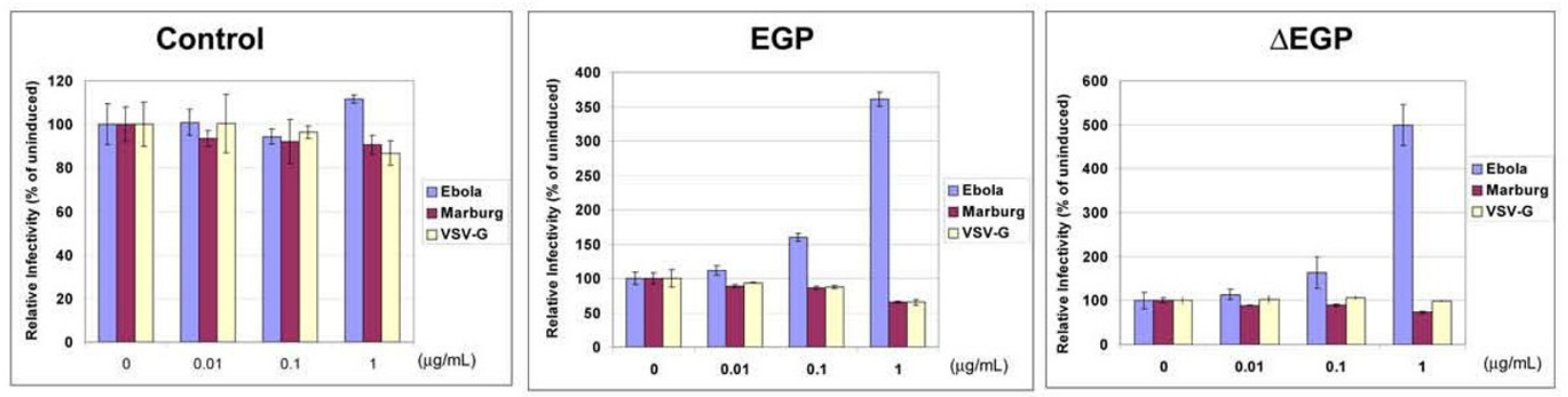

B
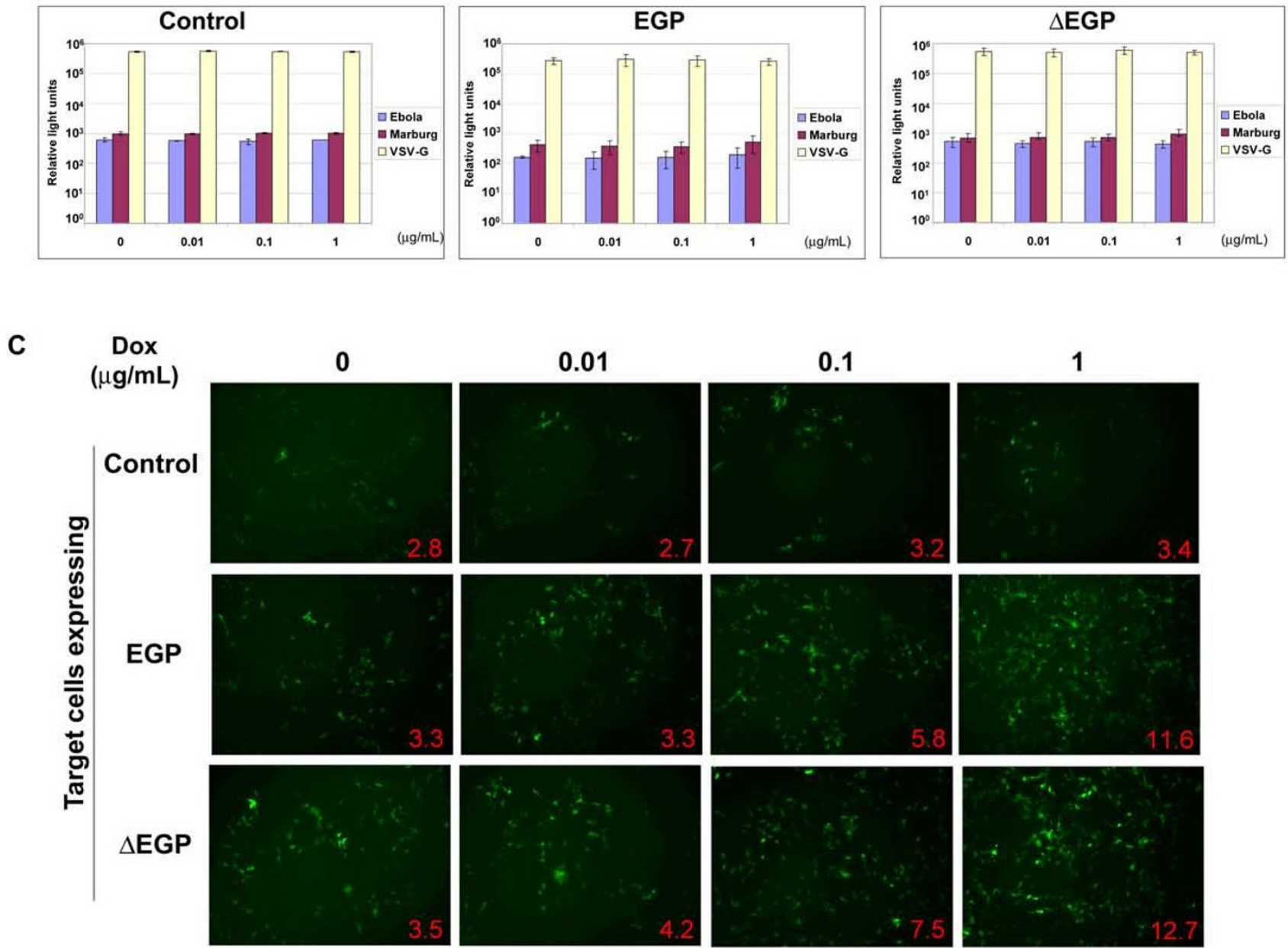

0.1
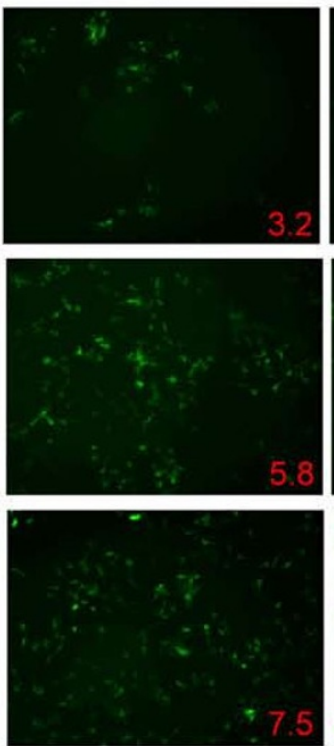

1
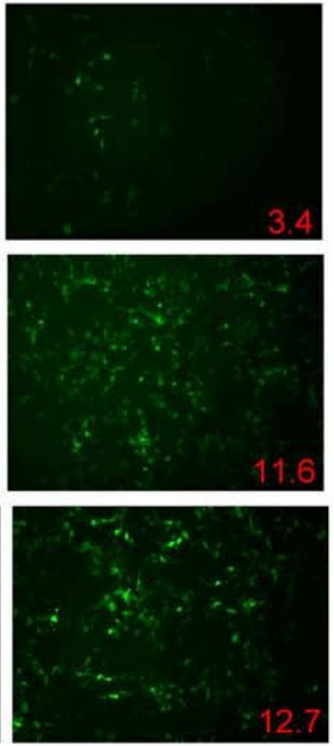

Figure 2 (see legend on next page) 
Figure 2 (see previous page)

GP enhancement is correlated with the entry susceptibility of the target cells. (A) EGP expression in HeLa cells enhances EGP/HIV transduction. HeLa Tet-On cells with EGP, $\triangle$ EGP or control vector were induced with dox and challenged with pseudotyped viruses. The luciferase activities were measured $48 \mathrm{~h}$ post-infection and are shown as percentage of the uninduced cells (100\%). Data represents an average of at least three independent experiments. Bars, standard deviations. (B) EGP expression in Jurkat Tet-On cells does not enhance EGP/HIV transduction. Jurkat Tet-On cells expressing EGP or $\triangle E$ EG or control vector were challenged with luciferase reporter virus and luciferase activity in the cell lysates are shown in relative light units (RLU). Data represents an average of at least three independent experiments. Bars, standard deviations. (C) Enhancement of EGP/MLV pseudovirus transduction in HeLa Tet-On cells. HEK Tet-On cells with EGP, $\triangle E G P$ or control vector induced with dox were challenged with $\triangle E G P / M L V$ pseudovirion carrying a GFP reporter. The percentage of GFP expressing cells are shown as inserts in each panel.

that the fusion function, rather than the receptor-binding function, of GP is involved in trans enhancement.

\section{Entry enhancement of Ebolavirus-like particles by EGP expression}

The entry pathways of EGP/HIV and EGP/MLV pseudoviruses are generally believed to faithfully mimic the Ebolavirus entry. However, Ebolavirus particles are filamentous, pleomorphic and morphologically distinct from retrovirus particles which are usually spherical. Previously, it has been shown that expression of EGP and the matrix protein VP40 in cells results in production of viruslike particles (VLPs), and these VLPs are morphologically similar to Ebolavirus particles[32]. Thus we have developed a modified $\beta$-lactamase based VLP entry assay to further investigate the EGP-mediated trans enhancement [24]. Modified $\beta$-lactamase protein was fused to the N-terminus of VP40 (Figure 4A) to create BlaM-VP40. Upon VLP fusion the viral matrix will be released into the cytoplasm and the $\beta$-lactamase activity in these cells can be used as a measure for the GP-mediated viral entry.

To examine if BlaM-VP40 could be incorporated into VLP, $293 \mathrm{~T}$ cells were transfected with BlaM-VP40 and EGP expressing plasmids. After $48 \mathrm{~h}$, the supernatants were collected and analyzed for BlaM-VP40 incorporation by western blot. BlaM-VP40 was efficiently incorporated in the VLPs (data not shown). However, the incorporation levels were slightly lower than the unmodified VP40. We next examined if the $\beta$-lactamase activity could be detected in target cells upon incubation with the VLPs. HEK cells were infected with EnvA/, EGP/, MGP/, or VSVG/VLP by spinoculation at $4{ }^{\circ} \mathrm{C}$ followed by incubation at $37^{\circ} \mathrm{C}$. After 3 hour incubation at $37^{\circ} \mathrm{C}$, the cells were stained with $\beta$-lactamase cleavable dye CCF2-AM or CCF4-AM for $1 \mathrm{~h}$ and immediately visualized under a confocal microscope (Figure 4B). Mock and EnvA/VLP incubated HEK cells (non-permissive for EnvA-VLP) were completely negative for $\beta$-lactamase activity (green), because EnvA, the glycoprotein of avian leucosis and sarcoma virus $A$, requires the cognate receptor Tva (which is absent in HEK cells) for viral entry [33,34]. In HEK cells infected with VSVG/VLPs, nearly $93 \%$ of the cells were $\beta$ lactamase postive (blue). In EGP/or MGP/VLP challenged HEK, $41 \%$ and $50 \%$ cells were positive for $\beta$-lactamase activity, respectively. These results indicate that this VLP system recapitulates the fusion/entry properties of the respective viral glycoproteins. Therefore, we chose to use this system as a safe and surrogate assay to further investigate the EGP-mediated trans enhancement.

We next examined if EGP expression in target cells could enhance fusion/entry of VLPs. Stable HEK Tet-On cells expressing $\triangle \mathrm{EGP}$ or EGP or mutant L561A were induced with 0 or $1 \mu \mathrm{g} / \mathrm{ml}$ of dox and challenged with wt/or mutant EGP/VLPs. In $\triangle E G P$ or Wt EGP expressing cells, only a slight increase in number of blue cells (fused with VLPs) was consistently observed for wt EGP/VLPs, giving $15 \%$ or $12 \%$ more blue cells under induced than uninduced conditions, respectively (Figure 4C). More significantly, approximately 1.5-2 fold increase in blue cells was observed for mutants L558A/VLPs and R580A/VLPs, demonstrating trans enhancement on the VLPs. In contrast, expression of $\triangle E G P$ or EGP in the target cells did not affect fusion/entry of mutants K95A/VLPs, consistent with the results using HIV pseudovirions (Figure 4C and $3 \mathrm{~A}$ ). These results further substantiate our notion that, like GP/ HIV pseudovirions, fusion/entry of GP/VLPs requires efficient binding of the VLPs to the target cells. Also consistent with the results of GP/HIV pseudovirions, the L561Aexpressing HEK cells did not enhance fusion/entry of wt or mutant GP/VLPs.

It is important to point out that although the general trend for trans enhancement is similar for both GP/HIV pseudovirons and GP/VLPs, there are some distinct differences for different mutants in mediating fusion/entry of VLPs compared to that of HIV pseudovirions. For example, mutant L561A, which is completely impaired in mediating viral entry measured by HIV pseudovirion entry assay ( $0.02 \%$ of wt GP, see Table 1$)$, is also defective using VLPs (Figure 4C). However, mutants K95A, L558A and R580A, which have lower levels of relative infectivity in the HIV-based entry assay ( $<8 \%$ of wt EGP), had higher 
A
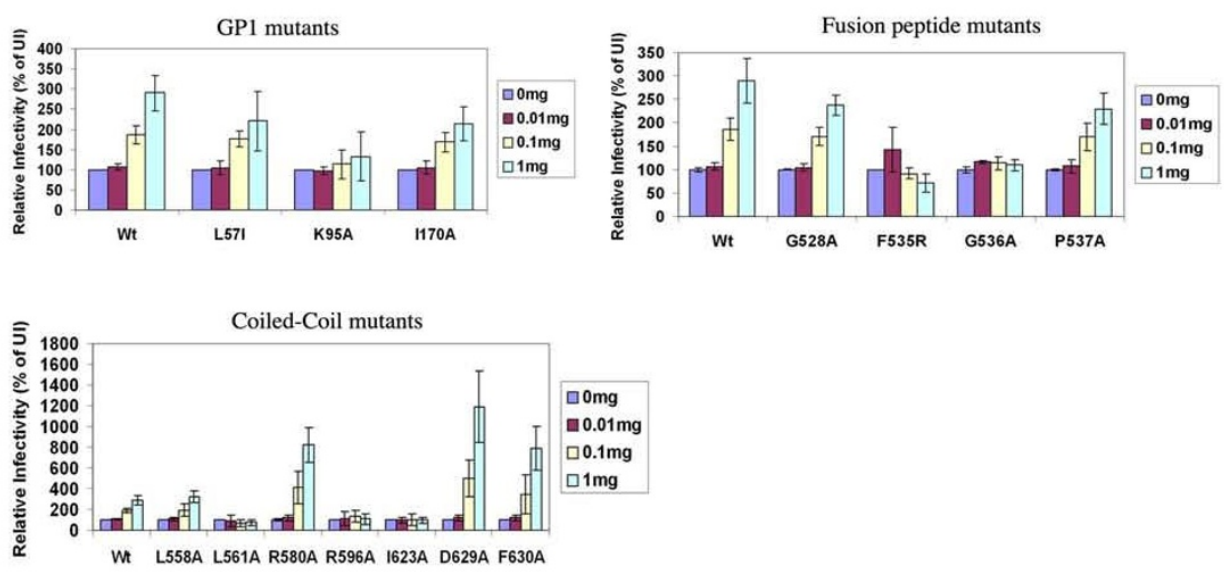

B

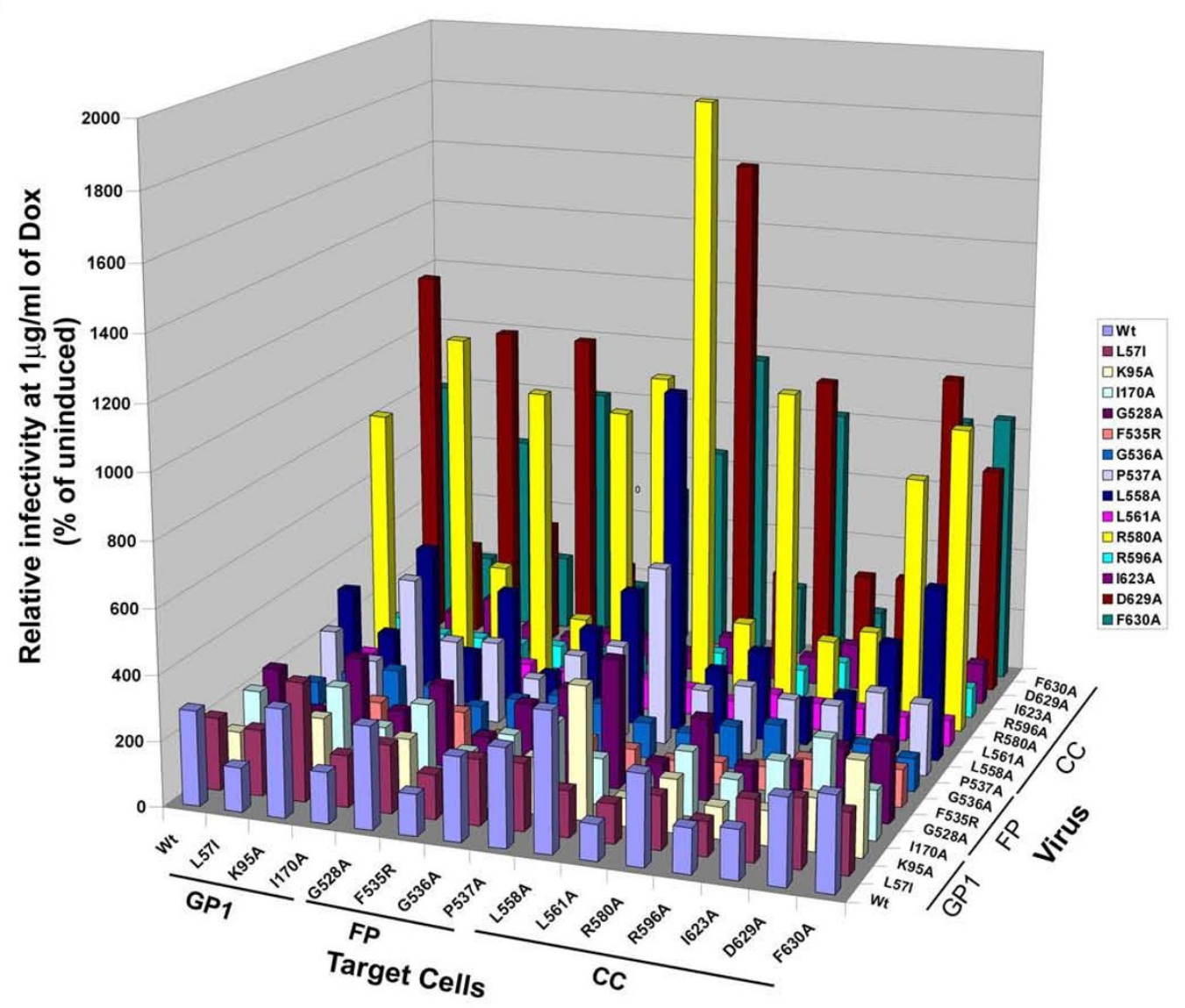

\section{Figure 3}

Analysis of Ebola GP mutants in trans enhancement process. (A) HEK Tet-On cells expressing Wt EGP were challenged with EGP mutant viruses, GPI mutants, relative infectivity of Wt and GPI mutant viruses. Fusion peptide mutants, relative infectivity of $\mathrm{Wt}$ and fusion peptide mutant viruses. Coiled-coil mutants, relative infectivity of Wt and GP2 mutant viruses. (B) Matrix analysis of trans enhancement by EGP. Wt or mutant EGP expressing HEK Tet-On was either uninduced or induced with I $\mu \mathrm{g} / \mathrm{ml}$ of Dox. After $24 \mathrm{~h}$, the cells challenged with pseudovirus particles carrying Wt or mutant EGP. The luciferase activities in infected cells are represented as relative percentage of luciferase activity in uninduced cells. Data represents an average of three independent experiments. For clarity of the chart we have omitted the error bars in panel B. 
Table I: Comparison of relative infectivity and enhancements for different EGP mutants

\begin{tabular}{ccc}
\hline Mutant & Relative Infectivity in 293T Cells (\%) & Relative Enhancement in Wt EGP Tet-On cells(\%) \\
\hline Wt & 100 & 290 \\
L57I & 9.50 & 221 \\
K95A & 4.00 & 133 \\
II70A & 26.10 & 213 \\
G528A & 74.42 & 238 \\
F535R & $\mathbf{0 . 0 2}$ & $\mathbf{7 I}$ \\
G536A & $\mathbf{0 . 0 7}$ & $\mathbf{1 0 9}$ \\
P537A & 3.37 & 230 \\
L558A & 6.92 & 324 \\
L56IA & $\mathbf{0 . 0 2}$ & $\mathbf{7 3}$ \\
R580A & 7.80 & 824 \\
R596A & $\mathbf{0 . 0 2}$ & $\mathbf{1 0 8}$ \\
I623A & $\mathbf{0 . 0 2}$ & $\mathbf{9 6}$ \\
D629A & 0.74 & 1188 \\
F630A & 0.68 & $\mathbf{7 8 9}$ \\
\hline
\end{tabular}

*Mutant completely defective in mediating viral entry are shown in bold font

levels of relative infectivity in the VLP based assay $(>50 \%$ of wt EGP). Further investigation is needed to elucidate these differences. Also, the observed differences in trans enhancement using HIV pseudovirion-based and VLPbased assays need to be further characterized in the future. Nevertheless, our results suggest that EGP expression in target cells can enhance Ebolavirus entry.

\section{Discussion}

\section{A molecular model for trans enhancement by EGP}

The results presented in the current study demonstrate that expression of EGP on the target cells can enhance EGP-mediated viral entry. Here we propose a molecular model based on our current understanding of this novel phenomenon (Figure 5). Ebolavirus binds to the target cells via interactions of the RBD of Ebola GP1 and the cellular receptor(s), and the attached virions are endocytosed into the endosomes (step 1). In the endosome, both the cell- and viral-anchored EGPs are cleaved by proteases cathepsin $\mathrm{B} / \mathrm{L}$, triggering a series of conformational changes on EGP which are essential for EGP-mediated membrane fusion. One of the required structural changes is to expose the fusion peptide of GP2, which is buried internally in the native, prefusion state of EGP trimer, and insert the fusion peptides to the opposing membrane (step 2). Concurrently or subsequently, the trimeric GP2 molecules on the virion (either in a pre- or post-six helical bundle form) "kiss" and "engage" the cell-anchored trimeric GP2 molecules, leading to formation of higher order GP2 oligomers consisting of at least two (likely multiple) GP2 trimers, with at least one trimer from the cellanchored GP2, initiating membrane fusion (step 3). Thus, bidirectional interaction of EGP enhances the later stages of fusion process such as hemifusion, fusion pore formation (step 4).
There are three important features in the current model which distinguish trans enhancement from the conventional view on EGP-mediated viral entry. First, geometrically, trans enhancement is coordinated by both viral- and host-anchored EGPs instead of the unidirectional mediation by the viral-anchored EGP alone. This bidirectional geometry of EGP-mediated viral entry is reminiscent of intracellular vesicle transport where the v-SNARE is carried on the transport vesicle and the t-SNARE on the target membrane, and the bidirectional $\mathrm{v}$ - and t-SNARE interaction mediates membrane fusion [35]. Also, EGP mediated fusion enhancement is analogous to the cell-cell fusion mediated by Caenorhabditis elegans proteins AFF- 1 and EFF-1 through the formation of trans homotypic oligomers $[36,37]$. The synergistic (or additive) effect of the GP2 molecules on the opposing membranes (bidirectional) may be more efficient than the GP2 on the viral membrane alone (unidirectional) in mediating viral/cell membrane fusion.

Second, physically, we propose that the fusion machinery, but not the receptor-binding function of the cell-anchored EGP is responsible for trans enhancement. This is in contrast to the role of the viral-anchored EGP in viral entry where both receptor-binding and fusion functions of EGP are required. The role of the fusion machinery of EGP in trans enhancement is demonstrated using a series of EGP mutants in this study. For example, mutant K95A, which is defective in mediating viral entry ( $4 \%$ of wt EGP) due to the impaired receptor-binding, could still trans enhance at a level similar to that of wt EGP. In contrast, two putative post-receptor binding mutants (L57I and I170A) displayed more impaired phenotype in trans enhancement (see Figure 3B). Based on our binding data and structure of EGP, it is clear that these residues are critical for trigger- 
A

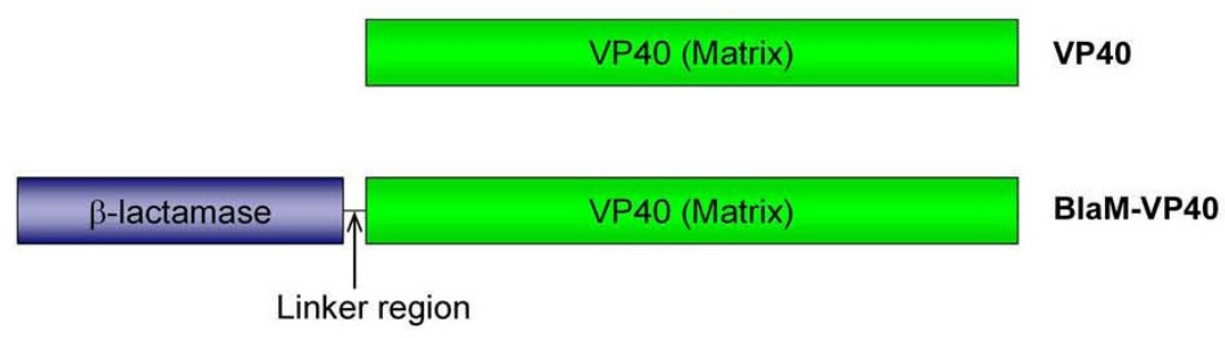

B

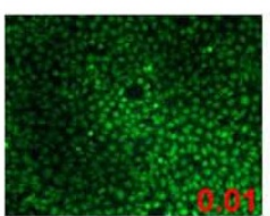

Mock

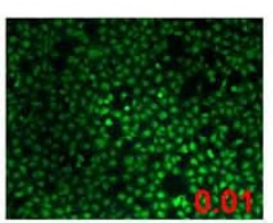

EnvA

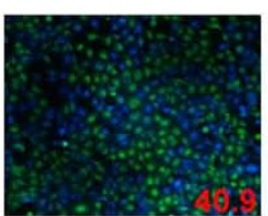

EGP

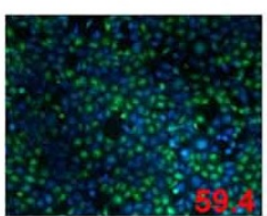

MGP

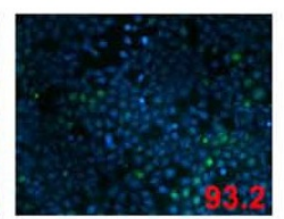

VSV-G
C

C

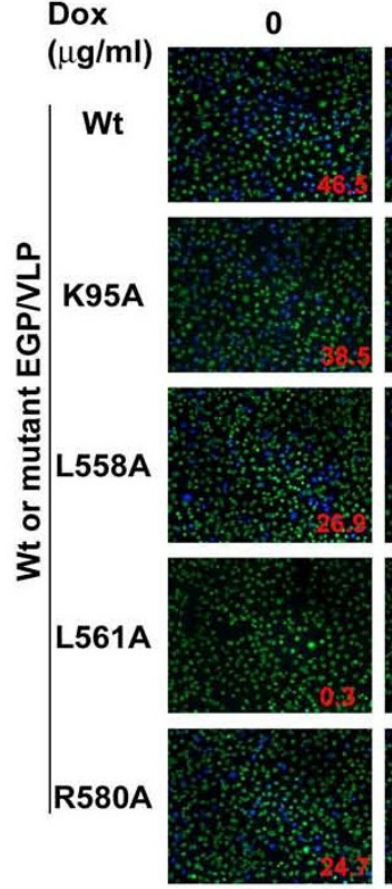

$\Delta$ EGP cells
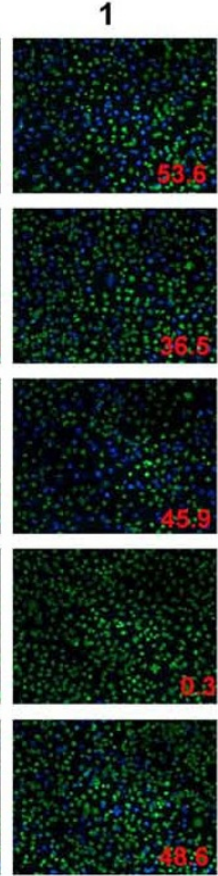

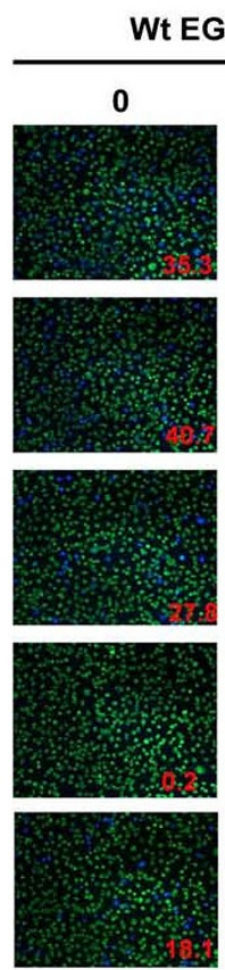

Wt EGP cells
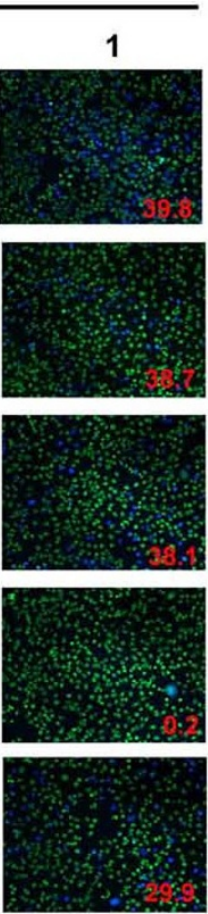

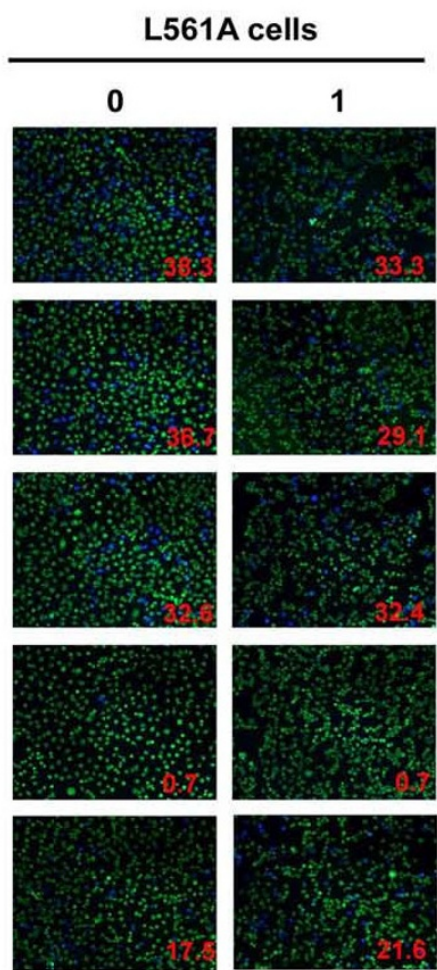

\section{Figure 4}

$\beta$-lactamase based Ebola VLP fusion assay. (A) Schematic representation of VP40 and BlaM-VP40 chimera. (B) BlaM based VLP fusion assay. HEK cells were infected by spinoculating at I,500 rpm for $2 \mathrm{~h}\left(4^{\circ} \mathrm{C}\right)$ followed by incubation at $37^{\circ} \mathrm{C}$ for $3 \mathrm{~h}$. The cells were loaded with CCF4-AM dye and analyzed by fluorescence microscopy. The percentage of infected cells were quantified by flow cytometry and shown as inserts. (C) BlaM VLP fusion assay in EGP expressing cells. EGP expressing cells challenged with Wt or mutant EGP carrying BlaM-VLP. The cells were loaded with CCF4-AM dye and analyzed by fluorescence microscopy. The percentage of infected cells were quantified by flow cytometry and shown as inserts. 
STEP 1

Receptor binding

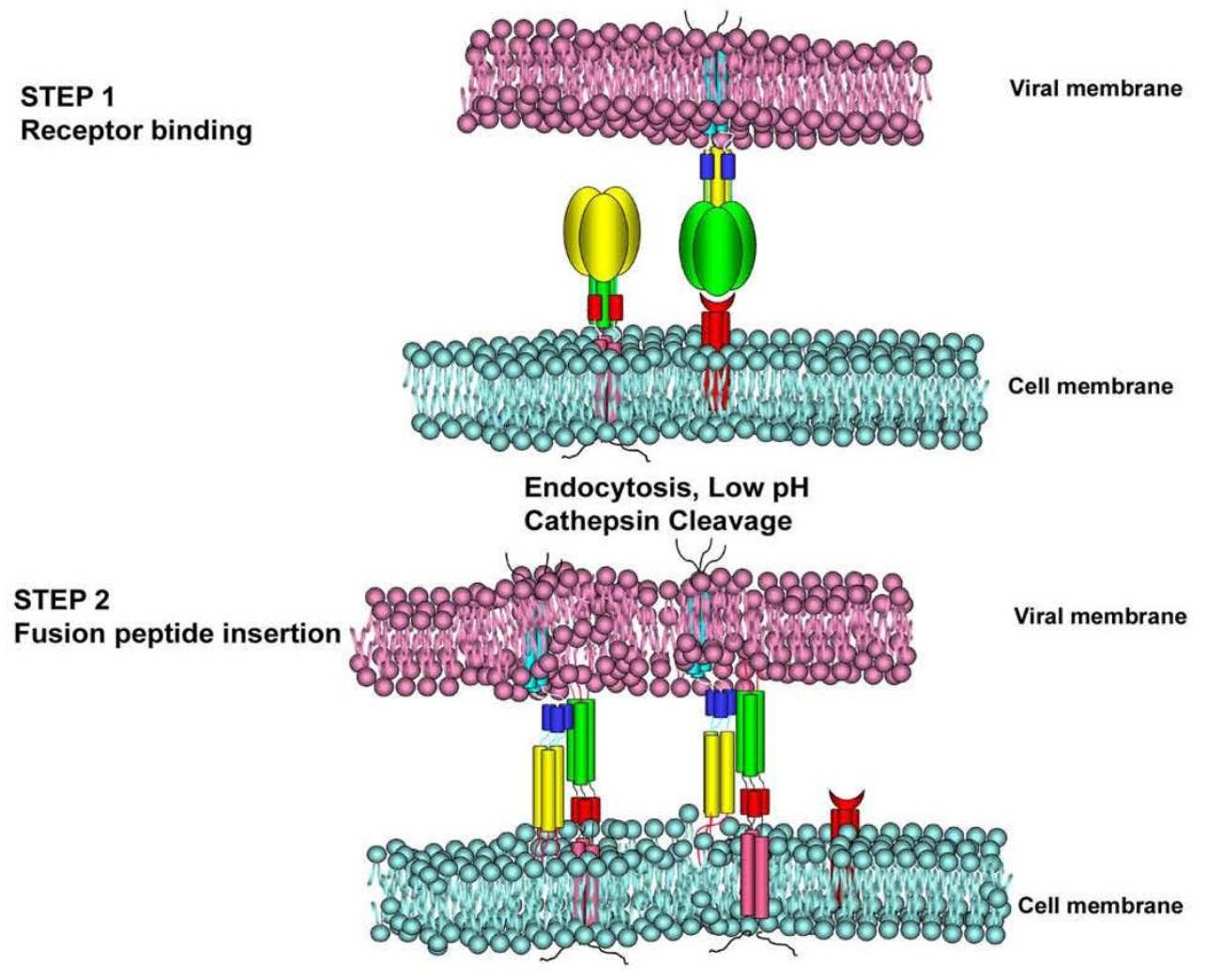

STEP 3

Initiation of membrane fusion

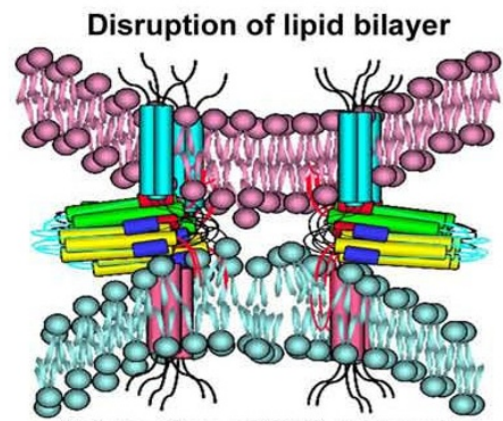

Interaction of GP2 molecules

STEP 4

Fusion pore formation

and release of viral

contents

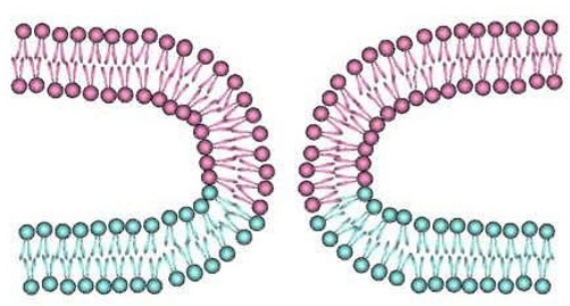

\section{Figure 5}

A proposed model for EGP-mediated enhancement. Step I. Receptor binding. EGP binds to its cell surface receptor(s). The bound virus is endocytosed into the cell, where it undergoes cleavage by cysteine proteases (cathepsin $B$ and $L$ ) under low $\mathrm{pH}$ environment. Step 2. Fusion peptide insertion. The fusion peptide from the virion EGP is inserted into the host membrane. Also, EGP of the target cell inserts to the viral membrane through the fusion peptide. Step 3. Initiation of membrane fusion. Conformational changes occur on EGPs and lead to direct contact and interaction between the viral membrane-anchored EGP and the cell membrane-anchored EGP, forming an oligomeric complex. Membrane fusion ensues. Step 4. Membrane fusion. Fusion pore forms and host-viral contents mix. 
ing the conformational changes on EGP which are critical for EGP-mediated membrane fusion. Further, several substitution mutations either in the fusion peptide or coiledcoil of GP2, the fusion subunit of EGP, were completely defective in facilitating trans enhancement (see Figures 3B). In addition, the most pronounced enhancement by EGP was on the mutants in the coiled-coil region (see Figure $3 \mathrm{~A}$ ). Together, these results strongly suggest that GP2, but not the receptor-binding function of GP1, is responsible for trans enhancement.

Third, mechanistically, we hypothesize that the cellanchored and viral-anchored EGPs interact and form higher order oligomeric structures, analogous to the transSNARE complexed formed by $\mathrm{v}$ - and t-SNAREs in vesicle transport [38]. Although the number of GP2 molecules required for fusion pore formation has not been reported, it is highly likely that multiple GP2 trimers are needed to promote membrane fusion based on our knowledge of influenza HA-mediated fusion[39]. The trans-EGP complex may provide a more efficient means than cis-EGP oligomers (present on virions) alone in promoting membrane hemifusion and fusion. The following observation is consistent with this hypothesis. Although evidence suggests that Ebola and Marburg viruses utilize same receptor(s) in viral entry, expression of EGP on the target cells had no enhancement effect on the MGP-mediated viral entry (see Figures 1 and S1). If trans enhancement did not require direct interactions between the cellanchored and viral anchored EGPs, we would predict that EGP on the cells could enhance MGP-mediated viral entry and vice versa. The inability of EGP to facilitate the MGPmediated viral entry is likely a result of sequence specificity required for trans enhancement. EGP and MGP share only approximately $28 \%$ amino acid identity [29]. Further, in contrast to EGP, the furin cleavage site of MGP is located within the mucin-like region, thus part of the mucin-like region resides in GP2 upon the protease cleavage [30]. Thus the sequence divergence between EGP and MGP may prevent the formation of the trans EGP/MGP oligomers, as proposed in Figure 5 for EGPs. In contrast, we speculate that the EGP-mediated trans enhancement may occur between Ebola species, since EGPs of these species share approximately $85 \%$ sequence homology. Evidence has been well documented for sequence-dictated specificity in protein-protein interactions in other systems. For example, mixed trimers between hemagglutinin proteins (HAs) derived from different influenza subtypes could not be detected experimentally because HA trimer formation is sequence specific [40]. In vesicle transport, the productive formation of the Trans-SNARE complex, comprising of a stable four $\alpha$-helix bundle, is almost exclusively by pairing v-SNARE with its cognate t-SNARE [41]. In contrast, for class I fusion proteins of the enveloped viruses including Ebola, the six $\alpha$-helix bundle is formed by homo-trimers $[19,20]$. Nevertheless, the formation of such oligomeric structures requires sequence specificity. Direct biochemical evidence awaits future work to demonstrate the formation of the trans-EGP complex, highly speculative at present, to validate the proposed model for EGP-mediated trans enhancement (see Figure 5). Furthermore, future studies on trans enhancement may provide mechanistic insights on class I fusion protein-mediated membrane fusion and viral entry.

\section{Dichotomous nature of Ebola GP: Interference versus enhancement}

Previously [30] and in this study, we have shown that overexpression of EGP in the target cells specifically blocks both the EGP- and MGP-mediated viral entry (see Figure S1). However, in the current study, we also demonstrate that using a Tet-On system, expression of EGP in the target cells enhances the EGP-, but not MGP-, mediated viral entry. These seemingly paradoxical observations, we believe, are due to the dichotomous nature of EGP: Low level expression of EGP on the target cells enhances viral entry via the fusion machinery, GP2. In contrast, high level expression of EGP on the target cells can sequester the Ebola receptor(s) by RBD of GP1 and thus lead to entry interference or superinfection resistance.

In conclusion, we have demonstrated that EGP expression at low levels in target cells specifically enhances EGPmediated transduction. The viral fusion machinery in the cell associated EGP specifically facilitates the enhancement of EGP-mediated viral transduction probably by trans oligomerization and cooperative interaction between virus/cell associated GP2 proteins via a mechanism analogous to vesicular membrane fusion and cellcell fusion.

\section{Methods \\ Cell lines and antibodies}

Human embryonic kidney (293T) cells were grown in DMEM supplemented with $10 \%$ FBS, penicillin and streptomycin $(100 \mathrm{U} / \mathrm{ml})$. Human cervical carcinoma (HeLa) Tet-On cells and Human embryonic kidney (HEK) Tet-On cells were grown in DMEM with 10\% tetracycline free FBS (Clontech). Human T-lymphocyte (Jurkat) Tet-On cells were grown in RPMI, 10\%FBS (tetracycline free), $10 \mathrm{mM}$ HEPES, $1 \mathrm{mM}$ sodium pyruvate, penicillin and streptomycin $(100 \mathrm{U} / \mathrm{ml})$. Ebola GP monoclonal antibody (12B5-11) was kindly provided by Dr. Mary K Hart (USAMRIID). HIV p24 monoclonal antibody was obtained from AIDS Reagent Program. $\alpha$-actin, goat anti-mouse-HRP and goat anti-mouse-FITC antibodies were purchased from Sigma.

\section{EGP expression vector construction and Mutagenesis}

The Ebolavirus Zaire glycoprotein gene (EGP) and mucin deletion mutant ( $\triangle \mathrm{EGP}$ ) expression vectors in pCDNA3.1 
plasmid have been described previously[16]. All alanine substitution mutations of the Ebola GP gene were generated by site-directed mutagenesis with the Stratagene QuickChange ${ }^{\circledast}$ Site-directed mutagenesis kit according to the supplier's protocols. All mutations were confirmed by DNA sequencing the entire coding region (CRC-sequencing facility, University of Chicago). To construct inducible GP expression plasmids, Wt or mutant GP were cloned into pREV-TRE vector under a tetracycline inducible minimal CMV promoter (Clontech).

\section{Generation of Tet-On cell lines}

HEK Tet-On cell line expressing recombinant tetracycline activator (rTA) was generated by transducing HEK cells with MLV based vector pREV-Tet-On according to manufacturer's protocol (Clontech). Transduced cells were selected with G418 at a concentration $800 \mu \mathrm{g} / \mathrm{ml}, 48 \mathrm{~h}$ post-transduction. EGP expressing cells were generated by transducing HEK Tet-On cells with MLV vector carrying EGP gene under tetracycline regulated promoter and selecting at $100 \mu \mathrm{g} / \mathrm{ml}$ concentration of hygromycin $\mathrm{B}$. Similarly, HeLa Tet-On (G418 $500 \mu \mathrm{g} / \mathrm{ml}$; hyrgromycin B $200 \mu \mathrm{g} / \mathrm{ml}$ ) and Jurkat Tet-On (G418 $2000 \mu \mathrm{g} / \mathrm{ml}$; hyrgromycin B $800 \mu \mathrm{g} / \mathrm{ml}$ ) cells were generated. After two weeks of selection, the cells were maintained in their respective media supplemented with G418 and hyrgromycin B (100 $\mu \mathrm{g} / \mathrm{ml}$ each).

\section{Analysis of EGP surface expression by flow cytometry}

HEK Tet-On cells bearing Wt or mutant EGP were seeded in 12-well plates $\left(6 \times 10^{4}\right.$ cells $)$ in $1 \mathrm{ml}$ of media without G418 or hygromycin B. EGP expression was induced with different concentrations of doxycycline $(0,0.01,0.1,1 \mu \mathrm{g} /$ $\mathrm{ml}$ ). After $24 \mathrm{~h}$, cells were washed once with $1 \mathrm{ml}$ of PBS and dissociated from the plates using Hanks dissociation buffer (Gibco). Cells were spun at $2000 \mathrm{rpm}$ and resuspended in $50 \mu \mathrm{l}$ PBS containing $2 \%$ BSA and $1 \mu \mathrm{g}$ of 12B51-1 antibody. After $30 \mathrm{~min}$ incubation on ice, the cells were washed twice with $300 \mu \mathrm{l}$ of PBS containing $2 \%$ BSA. The cells were resuspended in $50 \mu \mathrm{l}$ of PBS with $2 \%$ BSA and $0.25 \mu \mathrm{g}$ of goat anti-mouse FITC conjugated antibody. After 20 min incubation on ice, cells were washed twice in $300 \mu \mathrm{l}$ PBS-BSA buffer and resuspended in $100 \mu \mathrm{l}$ PBS-BSA buffer. EGP expression levels were measured by flow cytometry, using BD FACScalibur, gating for 20,000 live cells. The data were analyzed using WinMDI 2.8 software.

\section{Western blot}

HEK Tet-On cells were seeded in 12-well plate $\left(3 \times 10^{4}\right)$ in $1 \mathrm{ml}$ of media without G418 or Hyrgromycin B and EGP expression was induced with different concentrations of doxycycline $(0,0.01,0.1,1 \mu \mathrm{g} / \mathrm{ml})$. After $48 \mathrm{~h}$, the cells were lysed with $1 \%$ triton lysis buffer and analyzed by immunoblotting as described earlier[16]. Wt or mutant
GP expression and incorporation were determined as previously described[16].

\section{Production of pseudotyped virus}

GP/HIV pseudovirions for the infection assay and western blots were produced using three-plasmid based system [42]. In this system, the structural proteins (gag-pol) were provided in trans with the reporter gene expression vector carrying HIV RNA packaging signals (see Figure 1C). Briefly, 293T cells were co-transfected with $2.4 \mu \mathrm{g}$ of HR'CMV-Luc (luciferase reporter) or HR'-CMV-GFP (GFP reporter), $1 \mu \mathrm{g}$ of $\Delta 8.2$ (gag-pol), and $0.5 \mu \mathrm{g}$ of EGP or MGP or VSV-G plasmids using lipofecatamine ${ }^{\mathrm{TM}} 2000$.

\section{Infection assay in GP expressing Tet-On cells}

HEK Tet-On cells were seeded in 24-well plates at a density of $3 \times 10^{4}$ cells/well in $0.5 \mathrm{ml}$ media and induced with varying concentration of doxycycline $(0,0.01,0.1,1 \mathrm{mg} /$ $\mathrm{ml}$ ). After $24 \mathrm{~h}$, without removing the old media, cells were infected with $0.5 \mathrm{ml}$ of HIV pseudovirions carrying luciferease or GFP reporter gene. The media was replaced $12 \mathrm{~h}$ post-infection. The luciferase activities were measured $48 \mathrm{~h}$ post-infection as an indirect measure of GP mediated viral entry, and presented as percent infectivity of the uninduced cells. In the case of GFP reporter virus, infected were observed under a fluorescent microscope 72 $h$ postinfection and percentage of infected cells quantified using BD FACScalibur.

Enhancement Index $(\mathrm{EI})=$ Luciferase activity in induced $(1 \mu \mathrm{g} / \mathrm{ml}$ of Dox $) /$ Luciferase activity in uninduced $(0 / \mathrm{ml}$ of Dox $) \times 100$.

\section{VLP-based fusion assay}

(I) Construction of VP40 expression vectors

The Zaire Ebola VP40 gene was synthesized by multiple rounds of overlapping PCR based on EBOZ genome sequence (Gene accession number L11365). $\beta$-lactamase gene was PCR amplified from pCDNA3.1 vector and fused to N-terminal of VP40 to create a modified $\beta$-lactamaseVP40 fusion protein (BlaM-VP40) by a linker sequence (GSGGGSGGT). The modified $\beta$-lactamase lacks the $\mathrm{N}$ terminal 24 amino acids and His24 was substituted by Asp to create an optimal Kozak sequence (Invitrogen).

\section{(2) Production of VLPS}

Briefly, 293T cells were co-transfected with $3 \mu \mathrm{g}$ Bla-VP40 and $0.5 \mu \mathrm{g}$ glycoprotein plasmid (EGP or MGP or VSV-G or EnvA) using lipofecatamine ${ }^{\mathrm{TM}} 2000$. The supernatant containing the VLPs were collected twice $(24 \mathrm{~h}$ and $48 \mathrm{~h}$ post-transfection), combined and clarified of floating cell debris by centrifugation at 3,000 rpm for $10 \mathrm{~min}$.

\section{(3) VLP infection assay}

Target cells were seeded in 24-well plates at a density of 2 $\times 10^{5} \mathrm{cells} /$ well in $0.5 \mathrm{ml}$ media. After $24 \mathrm{~h}, 0.5 \mathrm{ml}$ of viral supernatant were added to each and spinoculated at 1,500 
rpm for $2 \mathrm{~h}\left(4^{\circ} \mathrm{C}\right)$. After $2 \mathrm{~h}$, the plates were incubated at $37^{\circ} \mathrm{C}$ for another $3 \mathrm{~h}$. The cells were washed once with HBSS to remove unbound virus and infected cells were detected by using LiveBLAzer -FRET B/G substrate according to manufacturer's recommendations (Invitrogen). The infected cells were visualized by Olympus XI70 microscope or quantified by flow cytometry using a CyAn ${ }^{\mathrm{TM}} \mathrm{ADP}$ (Dakocytomation).

\section{Competing interests}

The authors declare that they have no competing interests.

\section{Authors' contributions}

$\mathrm{BM}$ performed the experiments, BM and LR designed the experiments and drafted the manuscript.

\section{Additional material}

\section{Additional file 1}

Experimental Procedures. Experimental protocols for the additional files. Click here for file

[http://www.biomedcentral.com/content/supplementary/1743422X-6-75-S1.doc]

\section{Additional file 2}

Supplementary figure legends. Description of the additional figures. Click here for file

[http://www.biomedcentral.com/content/supplementary/1743422X-6-75-S2.doc]

\section{Additional file 3}

Fig. S1. Over-expression of $\triangle E G P$ blocks EGP/and MGP/HIV entry. Click here for file

[http://www.biomedcentral.com/content/supplementary/1743422X-6-75-S3.jpeg]

\section{Additional file 4}

Fig. S2. Cell surface expression of EGP in Tet-On cells.

Click here for file

[http://www.biomedcentral.com/content/supplementary/1743422X-6-75-S4.bmp]

\section{Additional file 5}

Fig.S3. Western blot analysis of EGP expression in Tet-On cells.

Click here for file

[http://www.biomedcentral.com/content/supplementary/1743422X-6-75-S5.tiff]

\section{Additional file 6}

Fig. S4. Analysis of EGP mutants.

Click here for file

[http://www.biomedcentral.com/content/supplementary/1743422X-6-75-S6.tiff]

\section{Acknowledgements}

We thank Jennifer LaMora, Viktor Volchkov, and the Rong Lab members for technical help and useful discussions. We also thank Thomas Hope
(Northwestern University) for providing the three-plasmid HIV pseudotyping system. The research was supported by National Institutes of Health grant Al 059570 (to L. R.).

\section{References}

I. Harrison SC: Viral membrane fusion. Nat Struct Mol Biol 2008, I5:690-698.

2. Eckert DM, Kim PS: Mechanisms of viral membrane fusion and its inhibition. Annu Rev Biochem 2001, 70:777-8I0.

3. Skehel JJ, Wiley DC: Receptor binding and membrane fusion in virus entry: the influenza hemagglutinin. Annu Rev Biochem 2000, 69:53।-569.

4. Kielian M, Rey FA: Virus membrane-fusion proteins: more than one way to make a hairpin. Nat Rev Microbiol 2006, 4:67-76.

5. Weissenhorn W, Hinz A, Gaudin Y: Virus membrane fusion. FEBS Lett 2007, 58 I:2I50-2I 55.

6. Earp LJ, Delos SE, Park HE, White JM: The many mechanisms of viral membrane fusion proteins. Curr Top Microbiol Immunol 2005, 285:25-66.

7. Colman PM, Lawrence MC: The structural biology of type I viral membrane fusion. Nat Rev Mol Cell Biol 2003, 4:309-319.

8. Yin HS, Paterson RG, Wen X, Lamb RA, Jardetzky TS: Structure of the uncleaved ectodomain of the paramyxovirus (hPIV3) fusion protein. Proc Natl Acad Sci USA 2005, 102:9288-9293.

9. Yin HS, Wen X, Paterson RG, Lamb RA, Jardetzky TS: Structure of the parainfluenza virus $5 \mathrm{~F}$ protein in its metastable, prefusion conformation. Nature 2006, 439:38-44.

10. Sanchez A, Khan AS, Zaki SR, Nabel GJ, Ksiazek TG, Peters CG: Filoviridae: Marburg and Ebola Viruses. In Fields Virology Volume 1. 4th edition. Edited by: Knipe DM, Howley PM. Philadelphia, PA: Lippicott Williams \& Wilkins; 200I:I279-I 304.

II. Feldmann H, Volchkov VE, Volchkova VA, Stroher U, Klenk HD: Biosynthesis and role of filoviral glycoproteins. J Gen Virol 200I, 82:2839-2848.

12. Jeffers SA, Sanders DA, Sanchez A: Covalent modifications of the ebola virus glycoprotein. J Virol 2002, 76: | 2463-12472.

13. Volchkov VE, Feldmann H, Volchkova VA, Klenk HD: Processing of the Ebola virus glycoprotein by the proprotein convertase furin. Proc Natl Acad Sci USA 1998, 95:5762-5767.

14. Wool-Lewis RJ, Bates P: Endoproteolytic processing of the ebola virus envelope glycoprotein: cleavage is not required for function. J Virol 1999, 73:1419-1426.

15. Sanchez A, Yang ZY, Xu L, Nabel G], Crews T, Peters CJ: Biochemical analysis of the secreted and virion glycoproteins of Ebola virus. J Virol 1998, 72:6442-6447.

16. Manicassamy B, Wang J, Jiang H, Rong L: Comprehensive Analysis of Ebola Virus GP I in Viral Entry. J Virol 2005, 79:4793-4805.

17. Kuhn JH, Radoshitzky SR, Guth AC, Warfield KL, Li W, Vincent MJ, Towner JS, Nichol ST, Bavari S, Choe H, et al.: Conserved receptor-binding domains of Lake Victoria marburgvirus and Zaire ebolavirus bind a common receptor. J Biol Chem 2006, 28 I: I595I-I5958.

18. Brindley MA, Hughes L, Ruiz A, McCray PB Jr, Sanchez A, Sanders DA, Maury W: Ebola virus glycoprotein I: identification of residues important for binding and postbinding events. J Virol 2007, 81:7702-7709.

19. Malashkevich VN, Schneider BJ, McNally ML, Milhollen MA, Pang JX, Kim PS: Core structure of the envelope glycoprotein GP2 from Ebola virus at I.9-A resolution. Proc Natl Acad Sci USA 1999, 96:2662-2667.

20. Weissenhorn W, Calder LJ, Wharton SA, Skehel JJ, Wiley DC: The central structural feature of the membrane fusion protein subunit from the Ebola virus glycoprotein is a long triplestranded coiled coil. Proc Natl Acad Sci USA 1998, 95:6032-6036.

21. Alvarez CP, Lasala F, Carrillo J, Muniz O, Corbi AL, Delgado R: CType Lectins DC-SIGN and L-SIGN Mediate Cellular Entry by Ebola Virus in cis and in trans. J Virol 2002, 76:684|-6844.

22. Chan SY, Empig CJ, Welte FJ, Speck RF, Schmaljohn A, Kreisberg JF, Goldsmith MA: Folate receptor-alpha is a cofactor for cellular entry by Marburg and Ebola viruses. Cell 200I, 106: I 17-126.

23. Lin G, Simmons G, Pohlmann S, Baribaud F, Ni H, Leslie G], Haggarty BS, Bates P, Weissman D, Hoxie JA, Doms RW: Differential Nlinked glycosylation of human immunodeficiency virus and Ebola virus envelope glycoproteins modulates interactions with DC-SIGN and DC-SIGNR. J Virol 2003, 77:1337-1346. 
24. Simmons G, Rennekamp AJ, Chai N, Vandenberghe LH, Riley JL, Bates $P$ : Folate receptor alpha and caveolae are not required for Ebola virus glycoprotein-mediated viral infection. J Virol 2003, 77:13433-13438.

25. Takada A, Fujioka K, Tsuiji M, Morikawa A, Higashi N, Ebihara $H$, Kobasa D, Feldmann H, Irimura T, Kawaoka Y: Human macrophage $\mathrm{C}$-type lectin specific for galactose and $\mathbf{N}$-acetylgalactosamine promotes filovirus entry. J Virol 2004, 78:2943-2947.

26. Shimojima M, Takada A, Ebihara H, Neumann G, Fujioka K, Irimura T, Jones S, Feldmann H, Kawaoka Y: Tyro3 family-mediated cell entry of ebola and marburg viruses. J Virol 2006, 80:10109-10116.

27. Chandran K, Sullivan NJ, Felbor U, Whelan SP, Cunningham JM: Endosomal proteolysis of the Ebola virus glycoprotein is necessary for infection. Science 2005, 308: 1643-1645.

28. Schornberg K, Matsuyama S, Kabsch K, Delos S, Bouton A, White J: Role of endosomal cathepsins in entry mediated by the ebola virus glycoprotein. J Virol 2006, 80:4I74-4I78.

29. Sanchez A, Kiley MP, Holloway BP, Auperin DD: Sequence analysis of the Ebola virus genome: organization, genetic elements, and comparison with the genome of Marburg virus. Virus Res 1993, 29:215-240.

30. Manicassamy B, Wang J, Rumschlag E, Tymen S, Volchkova V, Volchkov V, Rong L: Characterization of Marburg virus glycoprotein in viral entry. Virology 2007, 358:79-88.

3I. Hunter E, Swanstrom R: Retrovirus envelope glycoproteins. Cur Topic Microbiol Immun 1990, 1 57:187-253.

32. Watanabe S, Watanabe T, Noda T, Takada A, Feldmann H, Jasenosky LD, Kawaoka Y: Production of novel ebola virus-like particles from cDNAs: an alternative to ebola virus generation by reverse genetics. J Virol 2004, 78:999-1005.

33. Bates P, Young JAT, Varmus HE: A receptor for subgroup A Rous sarcoma virus is related to the low density lipoprotein receptor. Cell 1993, 74: 1043-I05I.

34. Rong $L$, Edinger $A$, Bates $P$ : Role of basic residues in the subgroup-determining region of the subgroup $A$ avian sarcoma and leukosis virus envelope in receptor binding and infection. J Virol 1997, $71: 3458-3465$.

35. Rothman JE: Mechanisms of intracellular protein transport. Nature 1994, 372:55-63.

36. Podbilewicz B, Leikina E, Sapir A, Valansi C, Suissa M, Shemer G, Chernomordik LV: The C. elegans developmental fusogen EFF-I mediates homotypic fusion in heterologous cells and in vivo. Dev Cell 2006, I I:47I-48I.

37. Shemer G, Suissa M, Kolotuev I, Nguyen KC, Hall DH, Podbilewicz B. EFF-I is sufficient to initiate and execute tissue-specific cell fusion in C. elegans. Curr Biol 2004, 14:1587-159|.

38. Sutton RB, Fasshauer D, Jahn R, Brunger AT: Crystal structure of a SNARE complex involved in synaptic exocytosis at 2.4 A resolution. Nature 1998, 395:347-353.

39. White JM: Membrane fusion. Science 1992, 258:917-924

40. Boulay F, Doms RW, Webster RG, Helenius A: Posttranslational oligomerization and cooperative acid activation of mixed influenza hemagglutinin trimers. J Cell Biol 1988, 106:629-639.

41. McNew JA, Parlati F, Fukuda R, Johnston RJ, Paz K, Paumet F, Sollner $\mathrm{TH}$, Rothman JE: Compartmental specificity of cellular membrane fusion encoded in SNARE proteins. Nature 2000, 407:153-159.

42. Naldini L, Blomer U, Gallay P, Ory D, Mulligan R, Gage FH, Verma IM, Trono $D$ : In vivo gene delivery and stable transduction of nondividing cells by a lentiviral vector. Science 1996, 272:263-267.

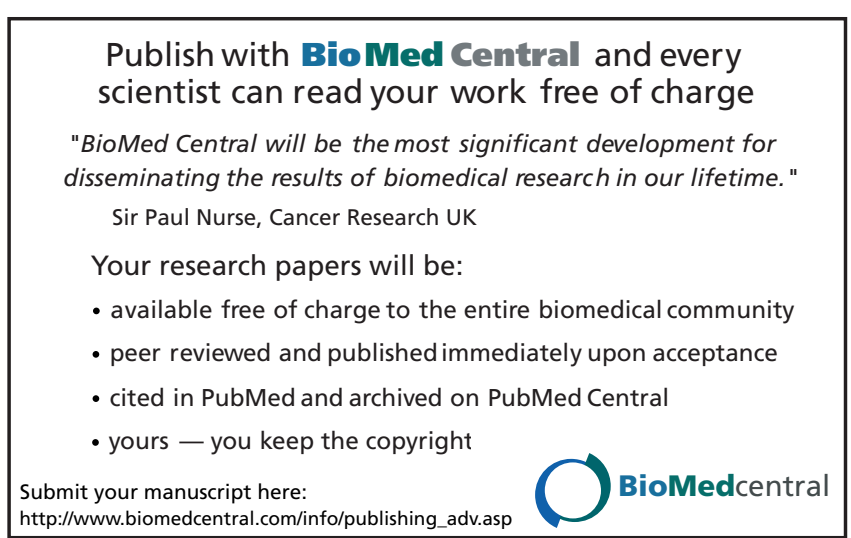

